\title{
DEVELOPMENT OF NOVEL SOL-GEL INDICATORS (SGI'S) FOR IN-SITU ENVIRONMENTAL MEASUREMENTS: PART I - PROGRAM AND A NEW pH SOL-GEL INDICATOR (U)
}

by R. R. Livingston

Westinghouse Savannah River Company

Savannah River Site

Aiken, South Carolina 29808

Other Authors:

L. Baylor

(WSRC)

G. G. Wicks

(WSRC)
WSRC-RP- -92-1276

DE93 011704

A paper proposed for

Release to Technology Transfer Customers

This paper was prepared in connection with work done under Contract No. DE-AC09-89SR18035 with the U.S. Department of Energy. By acceptance of this paper, the publisher and/or recipient acknowledges the U. S. Government's right to retain a nonexclusive, royalty-free license in and to any copyright covering this paper, along with the right to reproduce and to authorize others to reproduce all or part of the copyrighted paper. 


\section{DISCLAIMER}

This report was prepared as an account of work sponsored by an agency of the United States Government. Neither the United States Government nor any agency thereof, nor any of their employees, makes any warranty, express or implied, or assumes any legal liability or responsibility for the accuracy, completeness, or usefulness of any information, apparatus, product, or process disclosed, or represents that its use would not infringe privately owned rights. Reference herein to any specific commercial product, process, or service by trade name, trademark, manufacturer, or otherwise does not necessarily constitute or imply its endorsement, recommendation, or favoring by the United States Government or any agency thereof. The views and opinions of authors expressed herein do not necessarily state or reflect those of the United States Government or any agency thereof.

This report has been reproduced directly from the best available copy.

Available to DOE and DOE contractors from the Office of Scientific and Technical Information, P.O. Box 62, Oak Ridge, TN 37831; prices available from (615) 576-8401, FTS 626-8401.

Available to the public from the National Technical Information Service, U.S. Department of Commerce, 5285 Port Royal Rd., Springfield, VA 22161. 
Keywords: Sol-Gel Indicators (SGI), $\mathrm{pH}$, environmental measurements, in-situ, glass

November 3, 1992

TO: $\quad$ L.M. Papouchado, 773A

C.R. Wolfe, 773A

T.V. Crawford, 773A

D.B. Moore-Shedrow, 773A

A.L. Boni, 773A

D.S. Kaback, 773-42A

C.E. Coffey, 773A

J.C. Corey, $773 \mathrm{~A}$

J.L. Steele, 773A

C.W. Jenkins, 773A

J.C. Griffin, 773A

P.E. O'Rourke, 773A

G.J. Hooker, 770A

FROM: Ron Livingston, Lewis Baylor, and George Wicks, 773A RRL \&LP gw
DEVELOPMENT OF NOVEL SOL-GEL INDICATORS [SGI's] FOR IN-SITU ENVIRONMENTAL MEASUREMENTS;
Part I- Program and a New pH Sol-Gel Indicator (U)

\section{INTRODUCTION}

The ability to monitor potentially hazardous materials in a timely and efficient manner is important for protecting the public and environment from consequences of undesirable chemical releases, as well as for supporting environmental 'clean-up' operations. These capabilities are critical throughout the DOE complex as well as for thousands of other processes throughout the commercial sector. In recent years, the need for remote monitoring instruments to both detect and quantitatively measure hazardous materials has been made even more acute by the multitude of recent environmental regulations that have been promulgated.

Authorized Derivative Classifier Elefenkun 
The Savannah River Technology Center (SRTC) formed a 'grass-roots', interdisciplinary team to investigate a new approach for remote monitoring of hazardous materials. The concept being explored includes development of a new class of materials to be used as sensing elements for chemical measurements (1). This technology involves incorporating 'indicator' materials, which change colors in the presence of constituents or conditions of interest, into specially prepared silica glass matrices. The technology is based upon sol-gel chemistry, which allows incorporation of the sensitive organic indicators without the use of high temperatures, into a glass matrix, which is both chemically durable and very porous, so species to be measured can enter the composite and effectively react with the indicator. The new composite, called Sol-Gel Indicator (SGI), can then be coated onto a variety of substrates, including analytical probes. The transparency of the composite allows photometric measurements to be made. This system is designed to be compatible with a portable analytical system that is capable of performing desired field measurements, such as in boreholes, streams, lakes, wells, soil, etc. The SGI system can be tailored to assess parameters of interest such as $\mathrm{pH}$, as well as detect and measure constituent; such as organics (gasoline, benzene, TCE, toluene, xylenes, etc.), heavy metal contaminants $(\mathrm{Hg}, \mathrm{Cd}, \mathrm{U}, \mathrm{Pb}$, etc.), and pesticides (DDT, methoxychlor, etc). This report summarizes a feasibility study of this concept and also includes the development of the first sensor examined, a sol-gel $\mathrm{pH}$ indicator (2).

\section{EXECUTIVE SUMMARY}

T.2e feasibility of incorporating analytical indicators into a sol-gel glassy matrix and then coating substrates with this composite material has been demonstrated. Substrates coated include paper, wood, glass, and the lens of an analytical probe. The first SRTC sol-gel indicator, comprising bromophenol blue dispersed in a silica matrix, was fabricated and successfully used to measure solution $\mathrm{pH}$ in the range of $\mathrm{pH} 3.0$ to 7.5. The material exhibited a quick response time, as measured by color changes both qualitatively and quantitatively, and the measuring device was reversible or reusable. Additional indicators with responses over other $\mathrm{pH}$ ranges as well as indicators sensitive to the presence of elements of interest, are also under development. The new SGI composites possess promising properties and an excellent potential for performing a variety of important in-situ environmental measurements. 
WSRC-RP-92-1276

\section{BACKGROUND}

Increased emphasis in recent years on environmental analyses spurred by various regulatory drivers has fueled a need for field portable and remote monitoring instruments. An important contribution to this effort has been the development of portable instruments such as the diode array spectrophotometers (DAS) and fiber-optic deployed sensors, which have made in-situ and remote spectroscopic measurements achievable. The component in fiber-optic DAS systems which allows flexibility in application is the fiber-optic probe which contains the sensing element or functions as a measurement cell. These probes, constructed from various materials, are small, rugged and are easily deployed. The hardware for such probes has been developed at SRTC over the past few years by O'Rourke and co-workers (3) and integrated into compact on-line and insitu spectrophotometer systems.

Such probes may function in several ways. Analytes may adsorb on the chemically modified probe surface or fiber tip. This alters the surface properties and subsequent light within the fiber (evanescent wave sensor). (4) These sensors may respond to several analytes or to a broad class of compounds. $\mathrm{pH}$ indicators have been immobilized in polymer matrices. (5) A polymer layer has itself been used as a high acid sensor (6) and as a salt sensor (7), and a fluorescent polymer has also been used as a high acid sensor (8). Some success has been achieved in fluorescence based sensors in which the indicator is chemically bound to a substrate or fiber surface. $(9,10)$ Other sensors for organic solvents $(11), \mathrm{CO}_{2}, \mathrm{pH}(12,13)$ and $\mathrm{NO}_{\mathrm{x}}$ (14), trap the color reagent inside an analyte-permeable membrane at the tip of an optical fiber. Sol-gel technology has opened up another possible route; the indicator may be trapped in a sol-gel glassy matrix. One effort underway utilizes a methoxy-silicate gel formulation to trap $\mathrm{pH}$ and metal ion indicators (15-17). Pore sizes of the sol-gel can be controlled during synthesis to allow the desired analyte to reach the indicator molecule, while keeping the indicator trapped. This technology has advantages over what currently exists by being able to incorporate the indicator at room temperature, so the organic material is not adversely affected, and is trapped in a chemically durable matrix. Other advantages are detailed in the Results and Discussion Section. 
WSRC-RP-92-1276

\section{EXPERIMENTAL PROGRAM}

Scoping studies have focused on creating sol-gel indicator compositions which adhere to a glass substrate and maintain desirable properties. Among the most important properties are (a) good indicator response (for measuring $\mathrm{pH}$, metals, halogenated organics, etc.), (b) low leachrate and (c) good surface quality (hardness, clarity \& uniformity). In addition to addressing these features, experimental efforts have also involved developing methods for producing uniform surtaces, evaluating effects of drying time and temperature, assessing application of drying control chemical additives (DCCA), and studying the impact of variations in sol-gel formulation. Our sample matrix for this first group of experiments to assess the feasibility of the concept, is shown in Table 1.

\section{SGI Formulations and Compositions}

Indicator Composition: A well respected analytical chemistry monograph on indicators (Bishop, 1972) catalogs more than 200 acid-base indicators, 200 metallochromic indicators and many redox indicators. These indicators span a wide range of the $\mathrm{pH}$ scale, allowing hydrogen ion concentration measurements to be made even at extreme values where $\mathrm{pH}$ meters are ineffective. Metallochromic indicators allow sensitive measurement of metals and metal ions and of many different circumstances without use of expensive equipment like inductively coupled plasma spectroscopy (ICP) or Auger emission spectroscopy (AES). Use of many of these indicators involves observation of a visible color change in the presence or absence of a selected material. Many of these indicators are commercially available, which will allow for extensive testing without the need for complex organic syntheses to produce indicator materials.

The SRTC sol-gel indicator program will evaluate several classes of indicators in support of environmental monitoring and remediation efforts. These tests will include indicators for acid-base $(\mathrm{pH})$, metals $(\mathrm{U}, \mathrm{Pb}, \mathrm{Hg}, \mathrm{Cd}$, etc) and volatile/halogenated organics (benzene, trichloroethylene, etc). The $\mathrm{pH}$ indicators with transitions in the visible wavelength range are available in several large classes based on chemical structure:

1) Sulphonephthaleins

2) Azo Dyes

3) Nitro Indicators
4) Phthaleins

5) Analinesulphonelphthaleins

6) Others

Bromophenol blue (BPB), used extensively in our early tests, is a sulphonephthalein. A second indicator in this same category which has 
been briefly evaluated is bromocresol green (BCG). BCG, though very similar in structure to BPB, was seen to require a modification of the basic sol-gel formulation to maintain response after drying of the thin film.

The metallochromic indicators are typically used for chelometric (e.g. EDTA) titrations. These indicators change color when complexed with various metals or metal ions. Most of these indicators respond to more than one metal, for example, several respond to all rare earth elements. Porphyrin compounds are also available for use as metal indicators. These compounds have more specific response to analytes of interest like $\mathrm{Hg}$ and $\mathrm{Cd}$, and their structure may be tailored to the metal ion of interest.

The volatile/halogenated organic indicators are typically organometallic complexes that are not readily available. However, we currently have one such compound (a $\mathrm{Pt} / \mathrm{Pd}$ organic salt) that responds reversibly to halogenated organics like carbon tetrachloride and hydrocarbons like octane.

Indicators that exhibit response to anions (ex. $\mathrm{Cl}^{-}, \mathrm{SO}_{4}{ }^{2-}, \mathrm{SCN}^{-}$) are available as adsorption indicators. However, the nature of these indicators requires the presence of metallic counter-ions that form insoluble complexes. The indicators respond to the insoluble complex, i.e. adsorb on the surface and change color, during precipitation. These may work as sol-gel indicators if the thin film also contains the required metal counter-ion. The availability of other indicators for anionic species is not known.

Our concept for sol-gel indictor (SGI) establishes a new class of materials. These materials are produced by trapping or chemically bonding indicator molecules in a sol-gel glass matrix. This can be accomplished at room temperature so heat-sensitive organic indicators are not adversely affected during fabrication. The product from marriage of sol-gel and indicator chemistry is expected to open new opportunities such as reagent strips used for spot tests, optically based sensors for in-situ measurements and various formulations for visual lab and field test measurements.

Sol-Gel Formulation: The primary sol-gel formulation is a mixture of ethanol (EtOH), water, and tetraethylorthosilicate (TEOS). This is the basic sol-gel formulation developed by Wicks (18), in the development of a sol-gel repair product (patent pending). Sol-gel chemistry allows glasses to be fabricated from organometallics, without the need of high temperatures. In the repair product developed at SRTC, alumina particles were suspended in a silica sol-gel glass matrix and used to plug leaks (19). Techniques for suspending and mixing particles in the glassy matrix were 
further refined in the development of SRTC sol-gel metal hydride systems (patents pending) used to store hydrogen (20-22). Techniques for distributing indicator in the sol-gel matrix are built upon these earlier efforts and utilize more effectively, the inherent porosity of the sol-gel process.

The sol-gel formulation is mixed according to SRS Disclosure No. S-64248. This mixture is then hydrolyzed by adding water to initiate polymerization, followed by polycondensation, thus producing an alcogel. Before drying and forming a gel and then a solid, the indicator material (a powder) is added to the liquid mix. The gel is then allowed to dry under ambient conditions via evaporation of the solvent, thus producing a silicabased xerogel containing indicator. During this procedure, the mixture could be fritted or deposited on a substrate, and was characterized by being very porous and containing a very high surface area. This allows the indicator to be incorporated or immobilized into a durable silica glass matrix, and due to the porosity of the surrounding glass, species of interest to be measured can migrate into the material and react with the trapped indicator. This produces a composite that is 'transparent and re-usable'.

Variations of this primary formulation were made by adjusting $\mathrm{pH}, \mathrm{EtOH}$, $\mathrm{HF}$, and $\mathrm{H}_{2} \mathrm{O}$ content. In general, $\mathrm{pH}$ and $\mathrm{H}_{2} \mathrm{O}$ content affect the rate and degree of cross linking of the TEOS molecules to form oligomers. This degree of cross linking affects pore size, pore volume, hardness and other qualities of the sol-gel indicator surface. EtOH content has its greatest effect in controlling viscosity of sol-gel indicator solutions. The viscosity plays a large role in determining film thicknesses and therefore, the adherence and mechanical integrity of film on the substrate. Film resistance to cracking and spalling during the drying steps was seen to improve with thinner films. The presence of fluoride ion has a similar effect to that discussed for $\mathrm{pH}$. The addition of HF to high $\mathrm{pH}$ sol-gel indicator solution was seen to initiate rapid condensation of sol gel and formation of solid materials.

\section{Applications}

Surface Preparation: Surfaces of substrates were prepared by several different techniques prior to coating with SGI formulations. These include etching with HF, solvent washing, detergent washing and combinations of these treatments. In the current study, all slides were initially detergent washed and rinsed several times with DI water to remove all initial surface oils, prior to further surface treatment. Solvent washing and HF etching (30 - 90 seconds) were seen to have similar effects on our ability to apply thin coats of SGI. Etching removed edge effects of 
the glass that had resulted in a build-up of SGI on glass edges and improved the long-term mechanical stability of the thickest coatings. However, for the initial scoping tests to determine indicator response and SGI durability, solvent (EtOH) wash was seen to te arequate and used most often because of its convenience.

Deposition Techniques: SGI coatings were applied using two basic techniques (a) drop method and (b) dip method. A modified drop method was used most frequently because it provided the simplest approach for working with a small volume of test solution. Experiments examined techniques to improve reproducibility of SGI film thickness and to coat larger surface areas. Thin surface coats of SGI are essential for good mechanical stability. Using a thin film reduces SGI cracking from internal forces caused by drying and differences in the expansion coefficients of SGI coating and substrate.

Substrates: A variety of substrates were tested in a cursory manner for compatibility with the SGI composite. At this point, SGI has been successfully bound to wood, paper, plastic, fiberglass and glass. Our studies to date have emphasized coating the SGI to glass substrates, including microscope slides and lenses in analytical probes. The glassy materials with thin films allow both qualitative and quantitative evaluation to be easily performed and the most convenient transition to existing field applications.

Porosity: Early experience with $\mathrm{pH}$ indicators has shown that sol-gel pore size is an important consideration in determining if an indicator has an adequate response to analyte. In addition to varying the $\mathrm{pH}$ of the sol-gel, other components such as DCCA may be added to affect pore size, thus allowing an otherwise inoperable system to maintain an adequate response. These additives, however, can have competing effects. For example, glycerin, one common type of DCCA, was seen to increase SGI pore size, but also degrade the mechanical integrity or hardness of the coating.

\section{Assessment Techniques}

Our assessment of sol-gel $\mathrm{pH}$ indicator performance in this preliminary work has been based mostly on observed color changes of the SGI composite (qualitative). In some cases, color changes have also been monitored quantitatively by spectophotometry. Only those formulations that respond to large $\mathrm{pH}$ changes, are considered for further evaluation. Other important properties assessed qualitatively in a pass/fail mode include (a) mechanical adherence/integrity (b) surface quality of the 
coating and (c) the chemical durability of the SGI (24 hour leaching test in deionized water).

\section{RESULTS AND DISCUSSION}

\section{Advantages of SRTC Sol-Gel Indicators}

The potential advantages of this new class of indicators include the following:

(a) the ability to incorporate known indicators into a solid matrix without the use of high temperatures, which could destroy or adversely affect the sensitivity of organic sensor materials

(b) the flexibility to tailor the sol-gel matrix so that it can incorporate different types of indicators that can perform different measurements. Hence, one or more types of indicators can be used to produce 'universal specialty probes' designed for 'multiple uses' and to fit specific customer's needs

(c) the ability to control the porosity of the sol-gel glassy matrix so species to be measured can easily impregnate the matrix and be measured by the indicator(s) inside the glass

(d) the ability to fabricate 'transparent' composites which can allow photometric analyses to be readily performed.

(e) provide a measuring system which can be 'reversible' so that the monitoring device can be reused

(f) provide a composite material (SGI) with desirable properties, i.e., good chemical durability and good mechanical, thermal and radiation stability.

(g) the ability to 'frit' the sol-gel indicator or to deposit it on a variety of substrates including paper, cloth, lenses, probes or fiber-optic devices, thus making the system particularly versatile, portable and compatible with support and field instrumentation.

\section{Glass Slide Substrates}

Glass slides were coated by various SGI compositions under study. The slides provided convenient substrates to look at a vast array of formulations quickly and inexpensively. The coated slides were then placed into buffered solutions of known $\mathrm{pH}$ where they changed colors. In Figures 1 and 2 , the materials studied are shown along with the qualitative color changes that were observed. The changes are very apparent in the range of $\mathrm{pH}$ values studied of 3.5 to 6.5 as seen in this photograph. Below and above this range, changes were not readily visible to the naked eye.

The reacted slides were also examined quantitatively by spectroscopy. The various $\mathrm{pH}$ values resulted in changes in the absorbance spectra as 
shown in Figure 3. These data and photographs clearly demonstrate the feasibility and effectiveness of the SGI concept and product.

\section{Probe Substrates}

In Figure 4, a complete fiber optic measuring system, including a glass lens coated with the SRTC SGI composite, is shown, and in Figure 5, the coated probe is viewed immersed in a solution and measuring $\mathrm{pH}$. These measurements are shown being performed in Figure 6. The device is sensitive to the $\mathrm{pH}$ of the solution. These data clearly show that the SGI can successfully be coated to an analytical probe and function effectively.

\section{Integrated Analytical System for Field Measurements} Our initial model for possible field application consists of a miniature diode array spectrophotometer (DAS) with fiber optic input coupled to a remote SGI coated lens assembly. The miniature DAS currently requires computer connection for operation; however, a lap top computer will frovide acceptable performance. The coated lens assembly is the basis for the sensor system. In operation, light from a small lamp will be focused onto one end of a fiber optic cable. Light exiting the distal end of the fiber will shine into the back end of a collimating lens that is coated on the front side with SGI. Light passes through the SGI where some of the light of particular wavelengths is absorbed by the indicator. The amount and wavelength of absorbed light is based upon indicator color and film thickness. Light exiting the SGI coated lens is reflected off a polished screen or mirror back into the lens. The lens reimages the reflected light onto a second fiber. The distal end of the second fiber is connected to the miniature DAS. Signals from the DAS are evaluated using chemometric techniques like multivariate analysis to provide readout/display of sensor response.

\section{FUTURE WORK}

The SGI task team is currently evaluating other $\mathrm{pH}$ sol-gel indicators that are sensitive to wider as well as additional $\mathrm{pH}$ ranges. The team will also examine the possibility of combining different indicators within the sol-gel matrix to fabricate tailored probes to meet 'universal' as well as more specific customer needs. These probes will then be evaluated as potential in situ environmental measuring devices for field use.

In order to move the technology out of the laboratory and into more practical applications, Mike Whitaker has joined the SGI team to help develop and apply sol-gel indicators to Flow Injection Analysis (FIA). One field application of this technique is to measure, what many consider to be 
the most important parameter associated with reactor moderator, $\mathrm{pH}$ in the range of 4 to 7 . The potential advantages of the SGI flow cells are (1) to quickly, accurately and efficiently make difficult $\mathrm{pH}$ measurements (2) to conduct these measurements at the source, i.e., in situ or in the field (3) to eliminate the need for transporting radioactive aliquots of solution and to minimize the amount of handling and subsequent exposure to personnel (ALARA) and (4) to minimize significantly the waste produced from conducting the $\mathrm{pH}$ measurements, since the quantities of radioactive solution to be measured can be very small and possibly returned to the source. The ability to measure reactor moderator $\mathrm{pH}$ more effectively is not only important to SRS defense oriented operations, but also to commercial power reactor operations. In addition, the use of the FIA system is relevant not only for conducting $\mathrm{pH}$ measurements, but can also be used to detect and quantify species of interest in a variety of other applications.

In addition to $\mathrm{pH}$ sol-gel probes, other indicators will be examined and the ability to measure species of interest, such as $\mathrm{U}, \mathrm{Hg}$, and $\mathrm{Pb}$ in the field, will be evaluated. Indicators will again be combined to tailor probes to measure individual or any group of relevant parameters, desired by customers. For example, this current technique of combining an analytical indicator with sol-gel has already been used to produce thin films that change color in the presence of uranium (in the form of $\mathrm{UO}_{2}{ }^{2+}$ ) in water. $\mathrm{A}$ sensor constructed using these thin tilms could be useful for monitoring uranyl in ground or surface waters. Additional work will be performed to evaluate the selectivity of this (arsenazo III) and other indicators for monitoring species of interest.

\section{REFERENCES}

1 O'Rourke, P., Wicks, G., Livingston, R. and Baylor L., "Sol-Gel Indicators, SRS Patent Disclosure SRS-92-269 (1992).

2 Livingston, R., Wicks, G., and Baylor L., "Sol-Gel pH Indicators, SRS Patent Disclosure SRS-92-337 (1992).

3 Van Hare, D., O'Rourke, P., Prather, W., Bowers, M. and Hovanec, M., "Online Fiber Optic Spectrophotometry, DP-MS-88-186 (1989).

4 Thompson, R.B. and Ligler, F.S., "Chemistry and Technology of Evanescent Wave Biosensors", Biosensors with Fiberoptics, Wise and Wingard, Jr., eds., Humana Press, NJ, pp.111-138 (1991).

5 Jones, T.P. and Porter, M.D., Anal. Chem., 60, pp. 404-406 (1988). 6 Carey, W.P., DeGrandpre, M.D. and Jorgensen, B.S., "Polymer-Coated Cylindrical Waveguide Absorption Sensor for High Aciditites", Anal. Chem., 61, pp. 1674-1678 (1989). 
7 McCurley, M.F., Seitz, W.R., "Fiber-Optic Sensor for Salt Concentration Based on Polymer Swelling Coupled to Optical Displacement", Anal. Chim. Acta, 249, pp. 373-380 (1991).

8 Carey, W.P. and Jorgensen, B.S., "Optical Sensors for High Acidities Based on Fluorescent Polymers", Appl. Spectrosc., 45, pp. 834-838 (1991).

9 Wangbai, M., Zhujun, Z., Seitz, W.R., "Poly(vinyl alcohol)- Based Indicators for Optical pH and Mg(II) Sensing", ACS Symposium Series, 403, pp. 273-282 (1989).

$10 \mathrm{Hool}, \mathrm{K} .$, Nieman, T.A., "Chemiluminescence Analysis in Flowing Streams with Luminol Immobilized on Silica and Controlled-Pore Glass", Anal. Chem., 59, pp. 869-872 (1987).

11 Dickert, F.L., Schreiner, S.K., Mages, G.R. and Kimmel, H., "Fiber-Optic Dipping Sensor for Organic Solvents in Wastewater", Anal. Chem., 61, pp. 2306-2309 (1989).

12 Wolfbeis, O.S., Weis, L.J., Leiner, M.J.P. and Ziegler, W.E., "Fiber-Optic Fluorosensor for C...ygen and Carbon Dioxide", Anal. Chem., 60, pp. 20282030 (1988).

13 Andres, R.T. and Sevilla, III, F.T., "Fibre-Optic Reflectometric Study on Acid-Base Equilibria of Immobilized Indicators: Effect on the Nature of Immobilizing Agents", Anal. Chim. Acta, 251, pp. 165-168 (1991). 14 Freeman, M.K. and Bachas, "Fiber Optic Sensor for $\mathrm{NO}_{\mathrm{x}}$ " L.G., Anal. Chim. Acta, 256, pp.269-275 (1992).

15 Zusman, R., Rottman, C., Ottolenghi, M. and Avnir, D., "Doped Sol-Gel Glasses as Chemical Sensors", J. Non-Cryst. Solids, 122, pp. 107-109 (1990). 16 Rottman, C., Ottolenghi, M., Zusman, R., Lev, O., Smith, M. Gong, G. Kagan, M.L., and Avnir, D., "Doped Sol-Gel Glasses as pH Sensors", Mater. Lett., 13, pp. 293-298 (1992).

17 Avnir, D., Brown, S., Ottolenghi, M., Zusman, R., "Doped Sol-Gel Glasses for Obtaining Chemical Interactions", European Patent Application \#91300458.6, Jan. 22 (1991).

18 Wicks, G.G., "Sol-Gel Ceramic Composite", SRS Patent Disclosure S-64248 19 Wicks, G.G., Tomas, M., Selden, E., Lopez, J., LeBert, R., Langton, C., and Ehrhardt, J., "Repair of the Middle Six Pack Leak in F-Canyon", DPST-88387 (1988).

20 Heung, L.K., Wicks, G.G. and Enz, G.L., "Formulation for a Glass-Metal Composite that Absorbs Hydrogen Reversibly", SRS Patent Disclosure SRS91-357 (1991).

21 Heung, L.K. and Wicks, G.G., "Catalyzed Absorption of Hydrogen Using a Porous Glass", SRS Patent Disclosure SRS-92-156 (1992).

22 Wicks, G.G. and Heung, L.K. , "Catalyzed Aerogels for Absorption of Hydrogen", SRS Patent Disclosure SRS-92-238 (1992). 


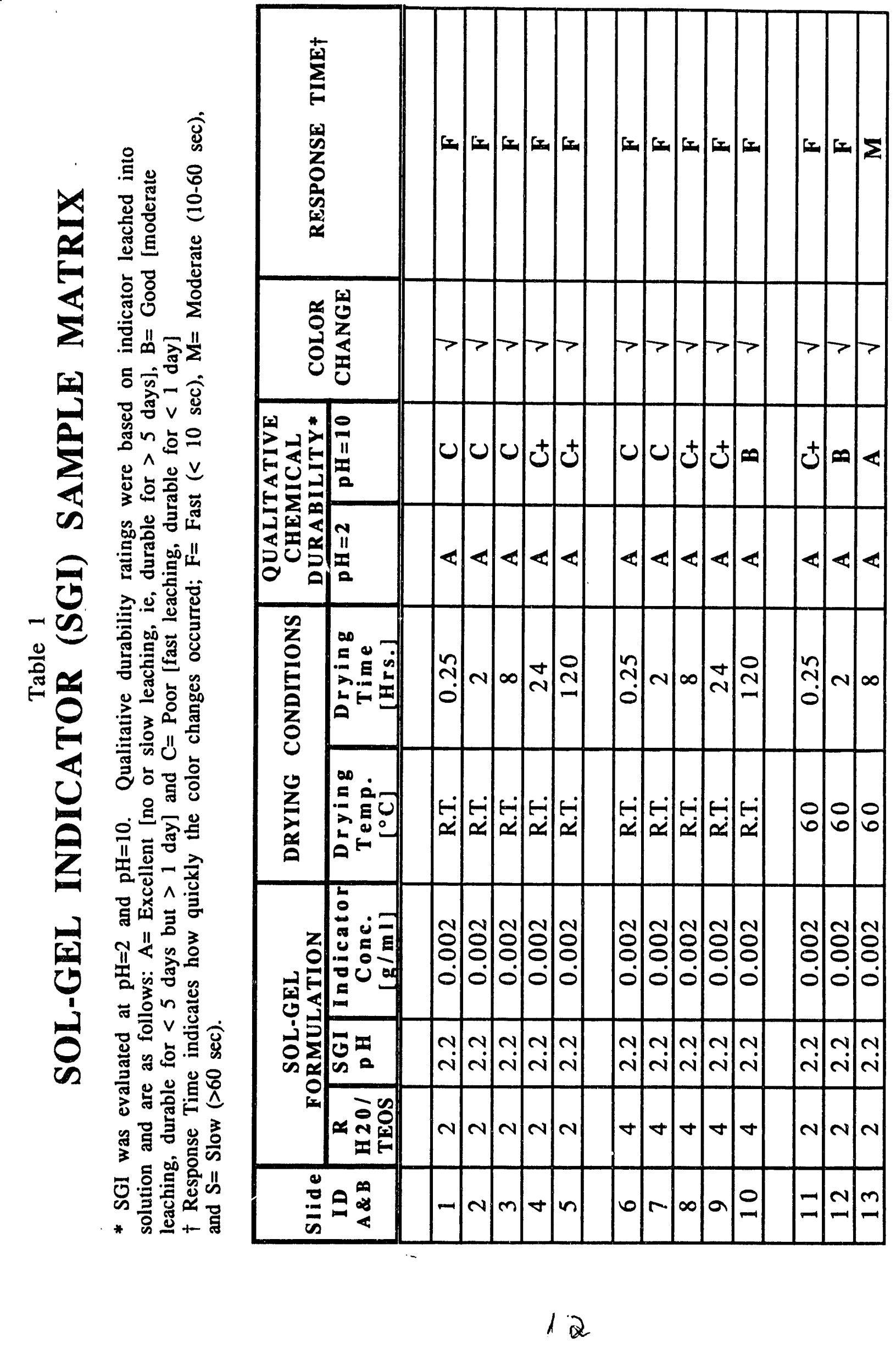




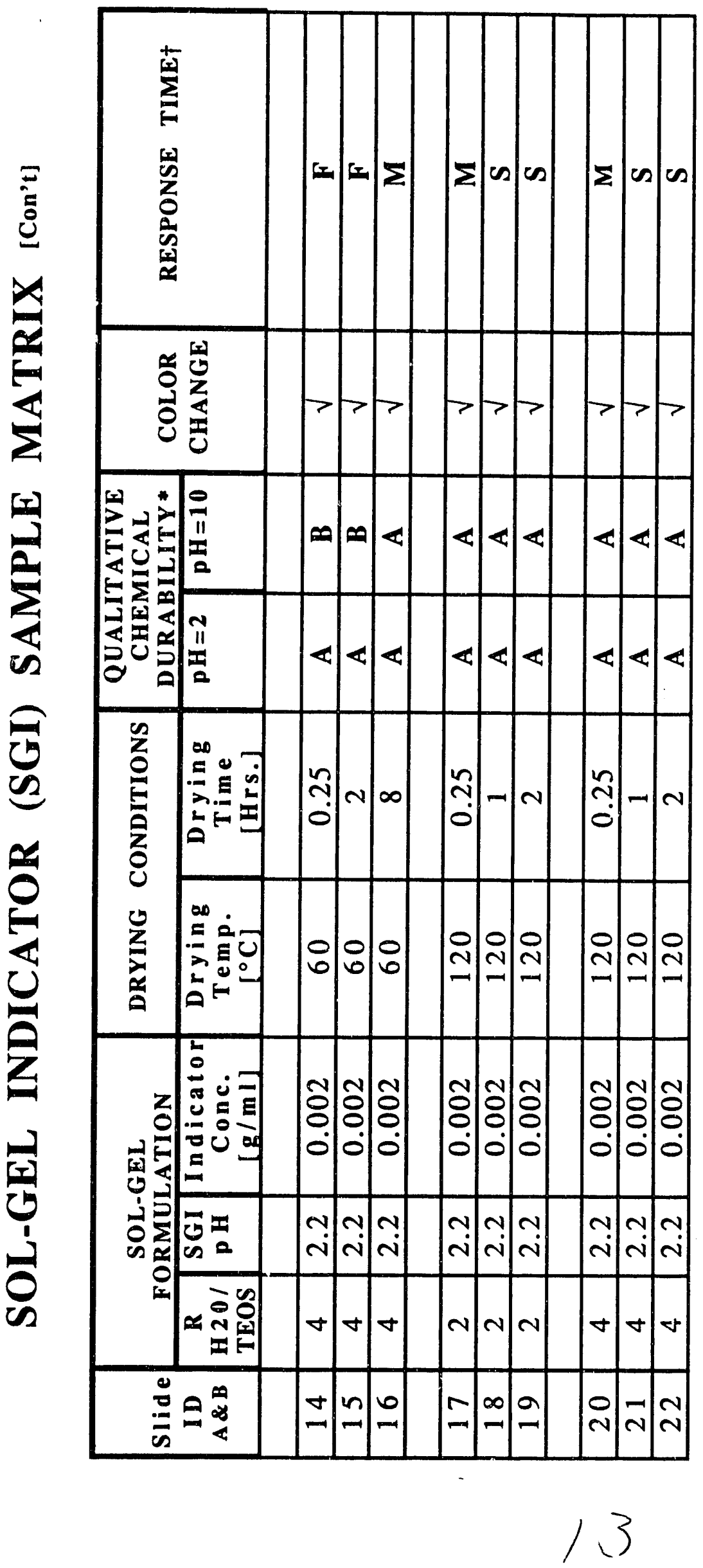


$\stackrel{\Perp}{ \pm}$

울

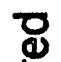

究 放

ธํㅇㅇ 을

능응

宁

ำ 당

농

4 的

ชงำ

으요 웅

2 증용

종응ㅇㅇ

눃ㅇ

뜬 픙궁

잉용

近需

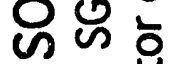

岁专告

-

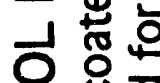

$20 \%$

푸

등 응

응

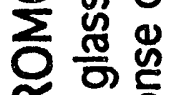

뚱응

ఖ

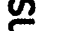

ธั

웛

$\stackrel{\Xi}{E}$ 


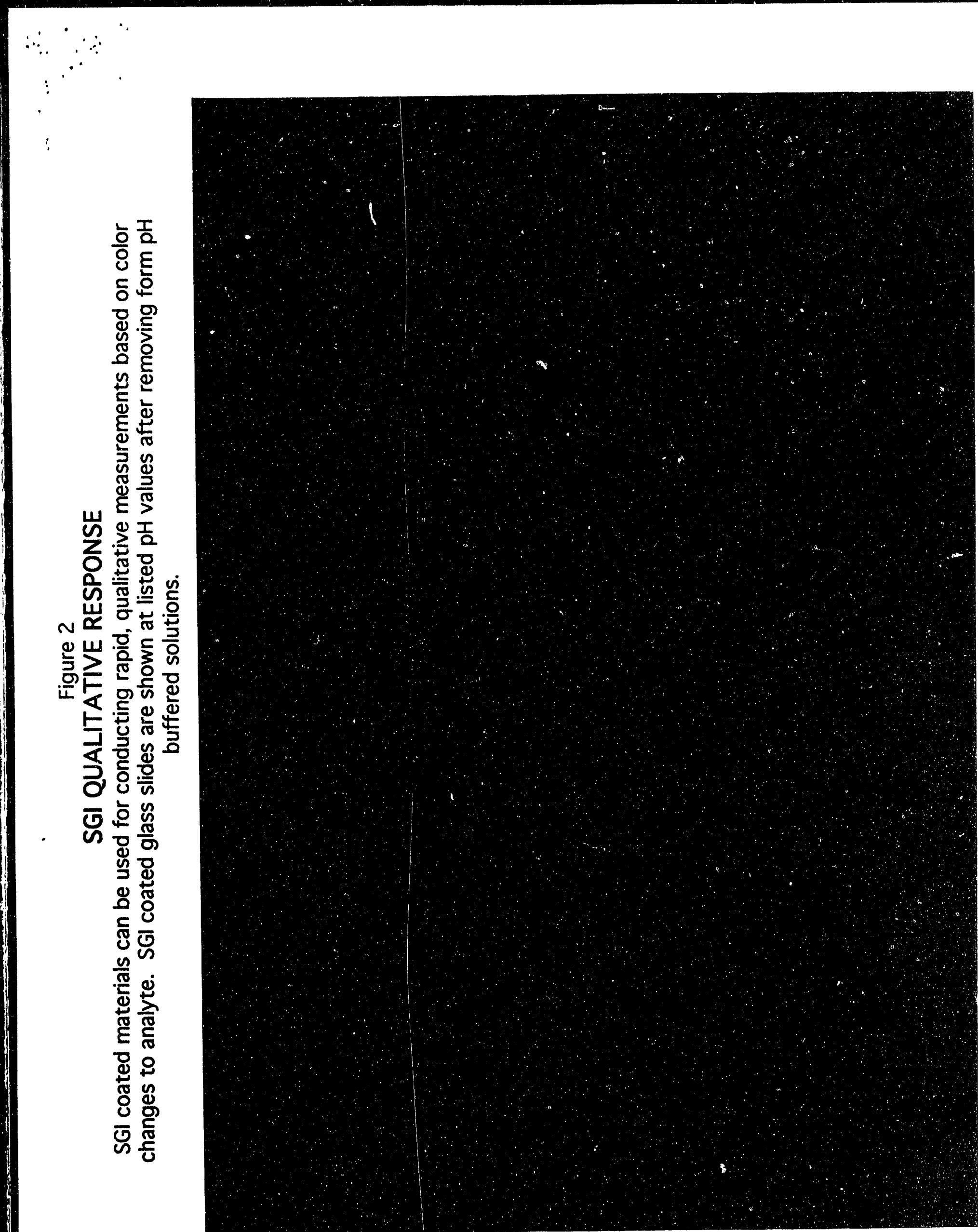



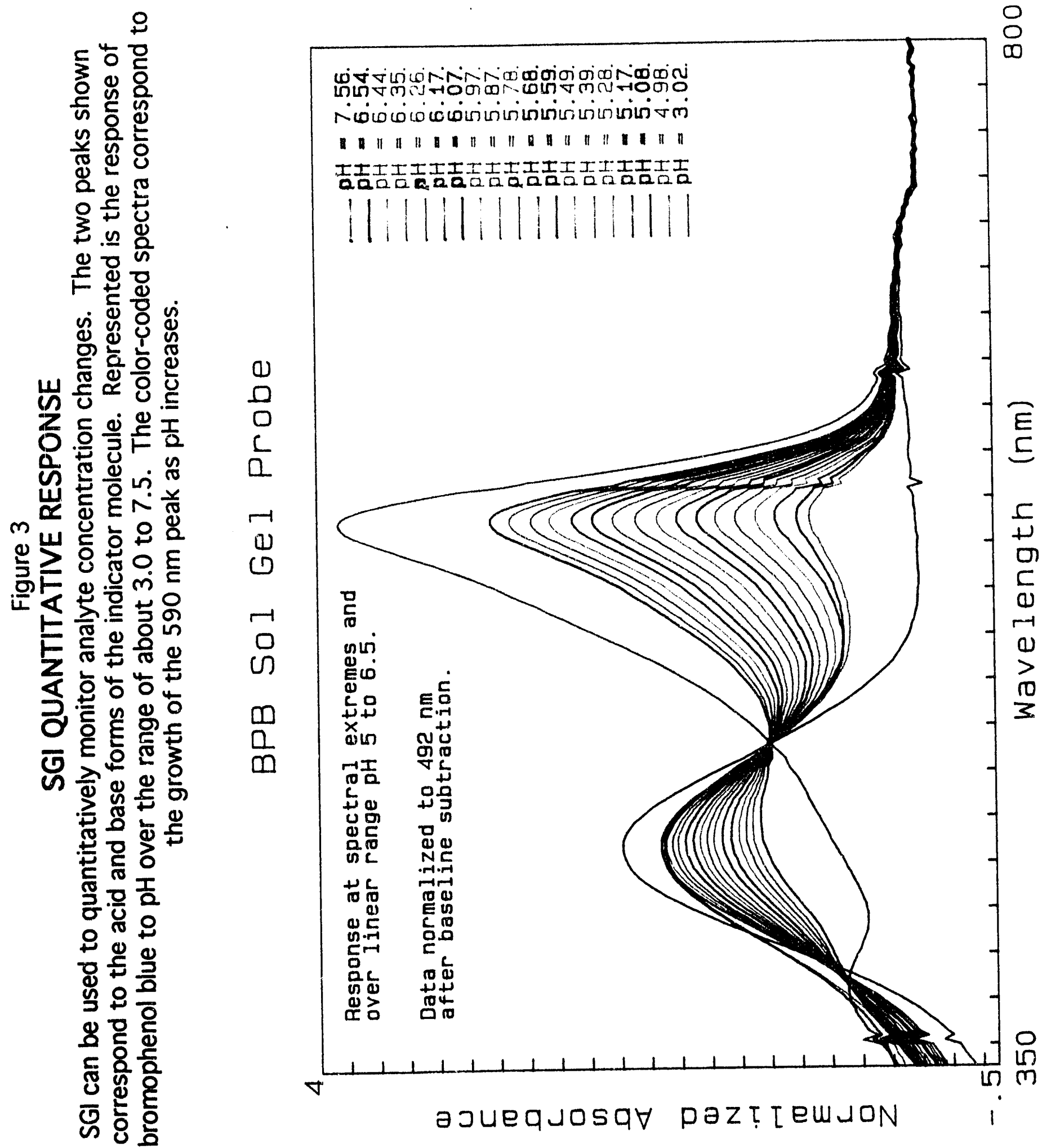
덩

$\stackrel{\Phi}{E}$

. 음

范

인 음

혼 응

4

(ำ

잉

종

山

ต

뜬

+ $\frac{1}{0}$

넌을 응

윤

证生乐

뜬ㅇㅇ

을 늘

बे

융

들

乡 ह

돔드

농

흥 응

웡

ิㅡ 잉

\%

$\Phi$

용

S

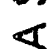




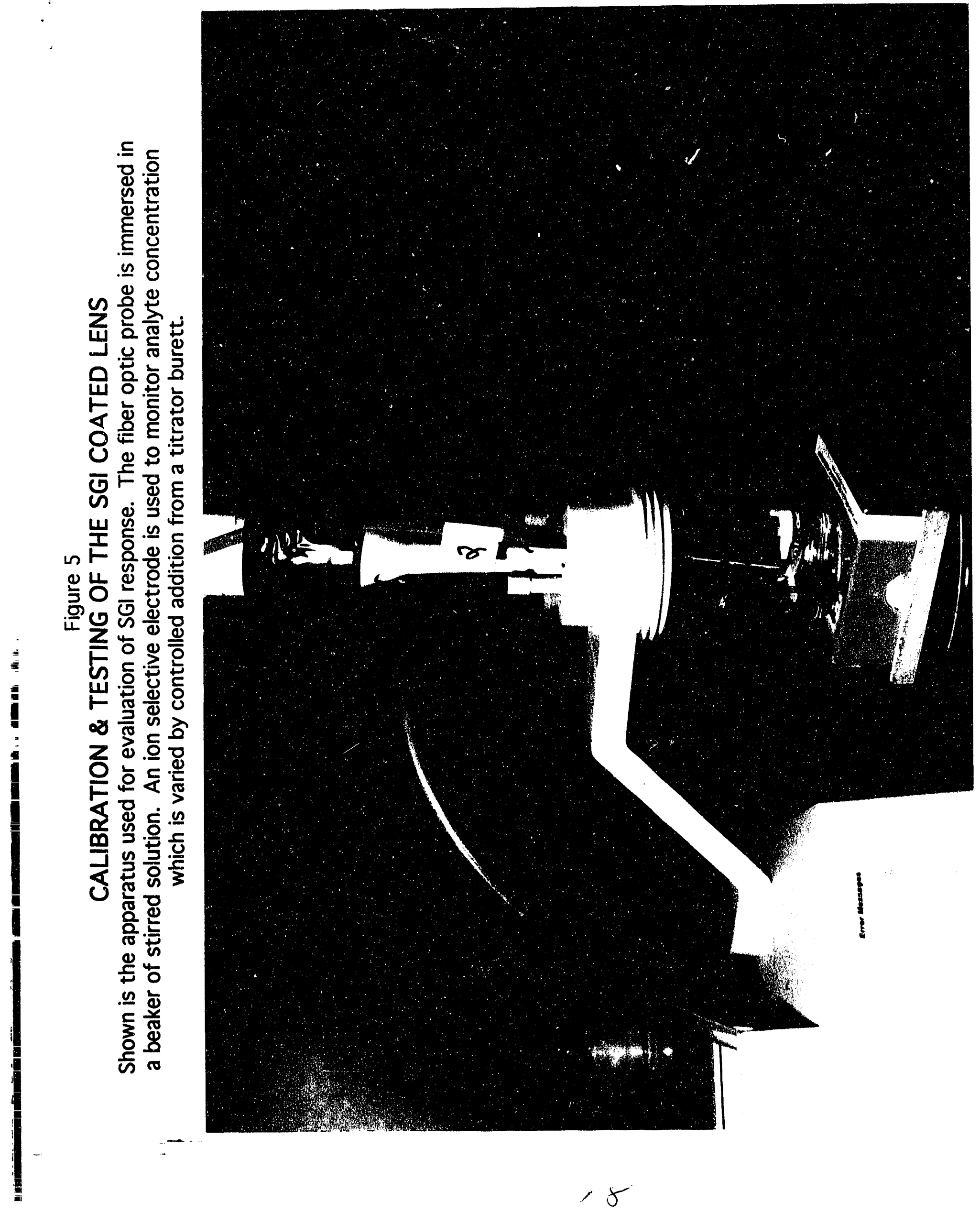




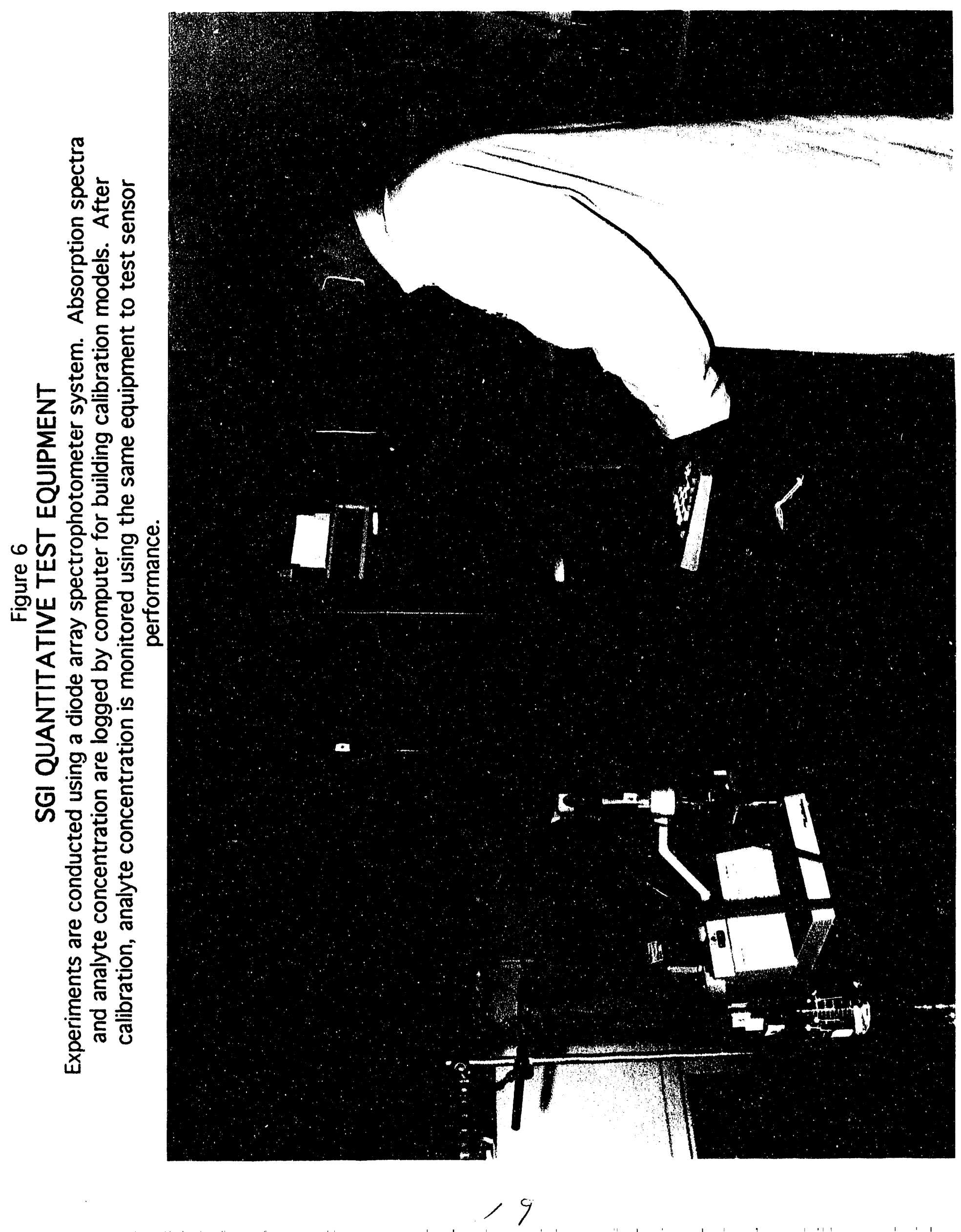



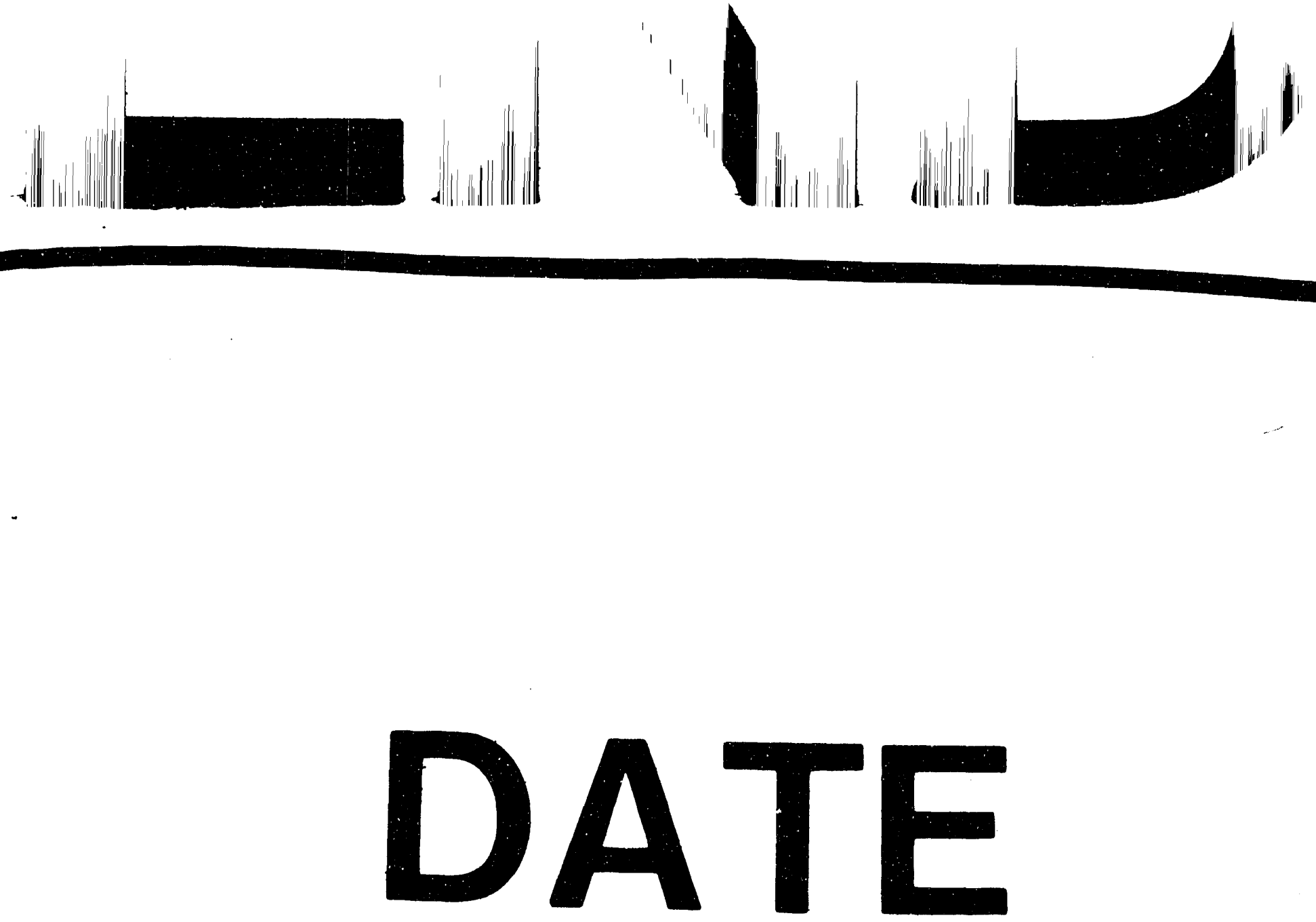

1
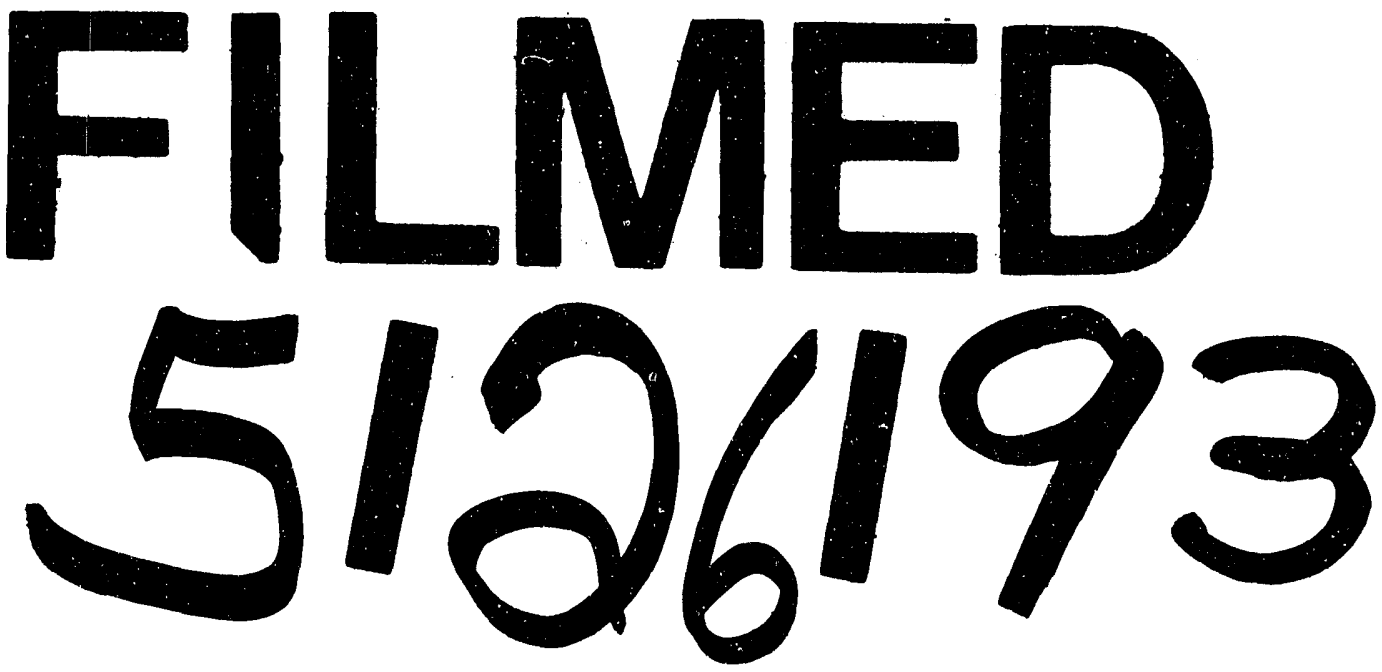
